\title{
Mapping of Powdery Mildew Resistance Gene pmCH89 in a Putative Wheat-Thinopyrum intermedium Introgression Line
}

\section{Liyuan Hou ${ }^{1}$, Xiaojun Zhang ${ }^{2,3}$, Xin Li ${ }^{2,3}$, Juqing Jia ${ }^{4}$, Huizhen Yang ${ }^{2}$, Haixian Zhan ${ }^{2,3}$,} Linyi Qiao ${ }^{2,3}$, Huijuan Guo ${ }^{2,3}$ and Zhijian Chang $2,3, *$

1 College of Life Science, Shanxi University, Taiyuan 030006, Shanxi, China; E-Mail: houliyuan0131@163.com

2 Institute of Crop Science, Shanxi Academy of Agricultural Sciences, Taiyuan 030031, Shanxi, China; E-Mails: zxjemail@163.com (X.Z.); leexinlee@aliyun.com (X.L.); 18636626922@163.com (H.Y.); zhan030006@126.com (H.Z.); qiaoly1988@126.com (L.Q.); ghj8067@126.com (H.G.)

3 Key Laboratory for Crop Gene Resources and Germplasm Enhancement on the Loess Plateau, Ministry of Agriculture, Taiyuan 030031, Shanxi, China

4 College of Agronomy, Shanxi Agricultural University, Taigu 030801, Shanxi, China; E-Mail: jiajuqing@126.com

* Author to whom correspondence should be addressed; E-Mail: wrczj@126.com; Tel.: +86-35-1713-0805; Fax: +86-35-1713-6763.

Academic Editor: Marcello Iriti

Received: 1 April 2015 / Accepted: 22 July 2015 / Published: 28 July 2015

\begin{abstract}
Powdery mildew, caused by Blumeria graminis f. sp. tritici (Bgt), is a globally serious disease adversely affecting wheat production. The Bgt-resistant wheat breeding line CH09W89 was derived after backcrossing a Bgt resistant wheat-Thinopyrum intermedium partial amphiploid TAI7045 with susceptible wheat cultivars. At the seedling stage, CH09W89 exhibited immunity or high resistance to Bgt pathotypes E09, E20, E21, E23, E26, Bg1, and $\mathrm{Bg} 2$, similar to its donor line TAI7045 and Th. intermedium. No Th. intermedium chromatin was detected based on genomic in situ hybridization of mitotic chromosomes. To determine the mode of inheritance of the Bgt resistance and the chromosomal location of the resistance gene, CH09W89 was crossed with two susceptible wheat cultivars. The results of the genetic analysis showed that the adult resistance to Bgt E09 in CH09W89 was controlled by a single recessive gene, which was tentatively designated as pmCH89. Two polymorphic SSR markers, $X w m c 310$ and Xwmc125, were linked to the resistance gene
\end{abstract}


with genetic distances 3.1 and $2.7 \mathrm{cM}$, respectively. Using the Chinese Spring aneuploid and deletion lines, the resistance gene and its linked markers were assigned to chromosome arm 4BL in the bin 0.68-0.78. Due to its unique position on chromosome 4BL, pmCH89 appears to be a new locus for resistance to powdery mildew. These results will be of benefit for improving powdery mildew resistance in wheat breeding programs.

Keywords: wheat-Thinopyrum intermedium introgression line; Th. intermedium; powdery mildew; genetic analysis; molecular mapping

\section{Introduction}

Common wheat (Triticum aestivum L.) is the most widely cultivated and important staple food crop in the world, and is constantly challenged by many diseases such as powdery mildew and rusts. Powdery mildew, caused by Blumeria graminis f. sp. tritici (Bgt), is a globally serious disease of wheat. It often occurs in regions with cool and humid climates, resulting in severe yield reductions [1,2]. In China, especially in the southwestern region, powdery mildew is the most frequently occurring disease due to moderate temperatures and rainy conditions during the wheat growing season. Yield losses can surpass 100 million $\mathrm{kg}$ per year when powdery mildew epidemics occur [3]. However, powdery mildew pathogen populations are very dynamic due to the continuous appearance of new virulent pathotypes capable of overcoming widely used host resistance genes. As a result, many previously resistant wheat varieties become susceptible. Therefore, new sources of effective and durable resistance genes are required for breeding high-yielding cultivars. Selection of and field deployment of resistant varieties is the most economic, effective, and environmentally friendly approach to controlling the disease [4]. Thus, the discovery and utilization of new powdery mildew resistance genes have become common objectives for wheat geneticists and breeders worldwide.

Fifty-three formally designated major genes (Pm1-Pm53) [5-7] and over 100 quantitative trait loci (QTLs) [8,9] for resistance to powdery mildew have been identified on the 21 chromosomes in bread wheat. The majority (39) of them are derived from common wheat, and a minority (18) were transferred from wild relatives of wheat. Thinopyrum intermedium (Host) Barkworth and Dewey $(2 n=6 x=42$, $\mathrm{JJ}^{\mathrm{s}} \mathrm{S}$ ), an uncultivated relative of wheat, has many potentially useful agronomic characteristics that could be used in wheat breeding programs, such as wide adaptability and tolerance to cold, drought, and salinity.

Th. intermedium has been widely studied in research directed toward wheat improvement due to its immunity or resistance to many serious wheat diseases. Hence, a series of addition lines, substitution lines, and translocation lines have been developed over the past years and are available for both agronomic improvement and resistance breeding. To date, many multi-resistant lines have been developed by crossing susceptible wheat cultivars with resistant partial amphiploids as donor parents. So far, two powdery mildew resistance genes (Pm40 [10] and Pm43 [11]), one stem rust resistance gene ( $S r 44$ [12]), and one stripe rust resistance gene (Yr50 [13]) have been transferred from Th. intermedium into common wheat. Pm40, Pm43, Sr44 and Yr50 have been mapped to chromosomes 7BS, 2DL, 7D and $4 \mathrm{BL}$, respectively. 
CH09W89, a Th. intermedium-derived wheat introgression line, is highly resistant to powdery mildew. It exhibits resistance to powdery mildew under greenhouse conditions in Taiyuan, Shanxi province. We identified a number of wheat genotypes with effective resistance against common Chinese races. The purposes of the present study were to determine the resistance inheritance of and locate the new gene in the Th. intermedium-derived line CH09W89.

\section{Results}

\subsection{Powdery Mildew Responses}

CH09W89, wheat-Thinopyrum intermedium partial amphiploid TAI7045, and the Th. intermedium parent Z1141 were resistant to all seven Chinese Bgt races tested at the seedling stage, whereas wheat parents Jinchun 5, Jin T2250, Jintai 170, and Jinmai 33 were susceptible (IT 3-4) (Table 1, Figure 1). The resistant ITs (infection types) were similar to the donor wheat-Thinopyrum intermedium partial amphiploid TAI7045 (IT 0-0;) as well as the donor Th. intermedium accession Z1141 (IT 0).

Table 1. Seedling infection types (IT) on selected donor lines, parents, and controls to seven Bgt pathotypes.

\begin{tabular}{cccccccc}
\hline \multirow{2}{*}{ Line } & \multicolumn{7}{c}{ Bgt Pathotype } \\
\cline { 2 - 8 } & E09 & E20 & E21 & E23 & E26 & Bg1 & Bg2 \\
\hline Th. intermedium Z1141 $^{\prime}$ & 0 & 0 & 0 & 0 & 0 & 0 & 0 \\
TAI7045 & 0 & 0 & $0 ;$ & 0 & $0 ;$ & 0 & 0 \\
Jinchun 5 $^{\text {a }}$ & 4 & 4 & 4 & 4 & 3 & 4 & 4 \\
Jin T2250 $^{\text {a }}$ & 4 & 4 & 3 & 4 & 4 & 4 & 4 \\
CH09W89 $^{\text {Jintai 170 }}$ & 0,0 & 0 & 0 & 0 & 0 & 0 & 1 \\
Jinmai 33 $^{\text {b }}$ & 4 & 4 & 3 & 4 & 4 & 4 & 4 \\
SY95-71 $_{\text {Mianyang 11 }}^{4}$ & 4 & 4 & 4 & 4 & 3 & 4 & 4 \\
Jingshuang 16 $^{\text {b }}$ & 4 & 4 & 4 & 4 & 4 & 4 & 4 \\
\hline
\end{tabular}

${ }^{a}$ Wheat parent of TAI7045; and ${ }^{\mathrm{b}}$ wheat parent of CH09W89. Scores of 0-2 were classified as resistant and $3-4$ as susceptible reactions.

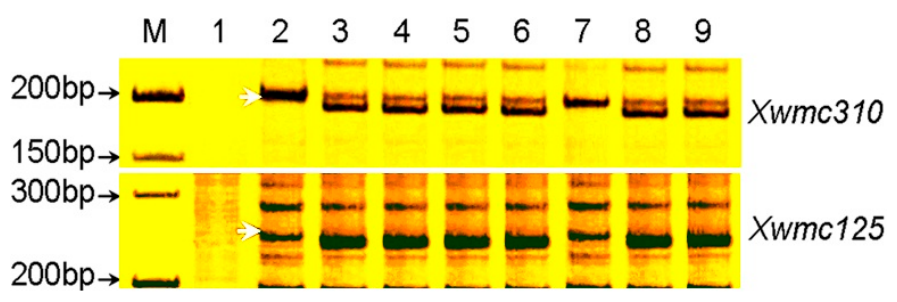

Figure 1. Silver-stained polyacrylamide gels showing simple sequence repeat (SSR) markers Xwmc310 and Xwmc125. Lanes 1: Th. intermedium Z1141; 2: TAI7045; 3: Jin T2250; 4: Jinchun 5; 5: Jinmai 33; 6: Jintai 170; 7: CH09W89; 8: SY 95-71; 9: Mianyang 11. Z1141, the accession of parent Th. intermedium; TAI7045, partial amphiploid and the resistant parent of CH09W89; Jin T2250 and Jinchun 5, the wheat parents of TAI7045; and Jinmai 33 and Jintai 170, the wheat parents of CH09W89. M: 100-bp DNA ladder. Arrows indicate polymorphic bands. 


\subsection{GISH Identification of Alien Chromatin in $\mathrm{CH} 09 \mathrm{~W} 89$}

GISH analysis was performed on somatic cells of both the resistant line CH09W89 and the recombinant control (line 03W006) using Th. intermedium genomic DNA as the labeled probe and Chinese Spring (CS) genomic DNA as blocker DNA. A pair of chromosomes revealed green fluorescence signals at the distal regions of their short arms in the positive control (Figure 2a). No visible hybridization signal could be found in CH09W89 (Figure 2b), indicating that no detectable wheat-Th. intermedium translocation is present in CH09W89. However, the translocated chromosome segment (if present) might be too small to be detected by GISH.
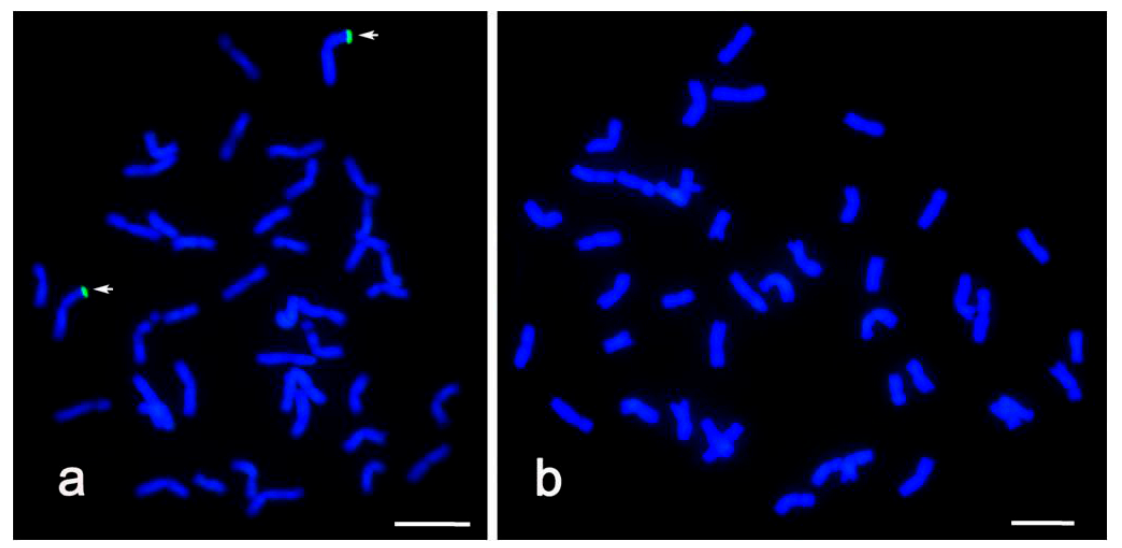

Figure 2. GISH pattern of lines 03W006, the wheat-Thinopyrum intermedium recombinant control (a) and CH09W89 (b) at mitosis using Th. intermedium genomic DNA as the probe. Arrows indicate alien chromatin. Scale bar $=10 \mu \mathrm{m}$.

\subsection{Inheritance of the Resistance to Powdery Mildew in CH09W89}

At the adult plant stage, when inoculated with race E09, $F_{1}$ plants from both crosses (SY95-71/CH09W89 and CH09W89/Mianyang) showed infection types (IT 3-4) similar to the susceptible parent, showing that the resistance gene was recessive (Table 2). Segregation in the $F_{2}$ and $\mathrm{BC}_{1}$ populations (Table 2) included many plants with intermediate responses. When the numbers of $\mathrm{F}_{2}$ plants with IT 0-2 and those with IT 3-4 were pooled as separate resistant and susceptible groups, the ratios were consistent with those expected for segregation at a single locus. When tested with the same race, the $\mathrm{F}_{2: 3}$ lines from SY95-71/CH09W89 and the $\mathrm{BC}_{1}$ plants from CH09W89/ MY11//CH09W89 segregated one homozygous resistant (HR): two segregating ( Seg): one homozygous susceptible $(H S)$, and one resistant: one susceptible, respectively, confirming segregation ratios for a single gene (Table 2). In addition, in segregating $F_{3}$ lines from SY95-71/CH09W89, the pooled numbers of resistant and susceptible plants were 1130 susceptible: 373 resistant $\left(\chi_{(3: 1)}^{2}=0.03\right.$, $\left.P_{1 \mathrm{df}}=0.87\right)$. These results suggested that a single recessive gene for resistance to powdery mildew was present in $\mathrm{CH} 09 \mathrm{~W} 89$, and was provisionally designated $\mathrm{pmCH} 89$. 
Table 2. Adult plant segregation ratios of powdery mildew response in $\mathrm{F}_{1}, \mathrm{~F}_{2}$, and $\mathrm{BC}_{1}$ plants, and $\mathrm{F}_{3}$ lines when inoculated with Bgt isolate E09.

\begin{tabular}{|c|c|c|c|c|c|c|c|c|c|c|}
\hline \multirow{4}{*}{ IT } & \multirow{2}{*}{\multicolumn{3}{|c|}{ Parent }} & \multicolumn{5}{|c|}{$\mathbf{P}_{2} / \mathbf{P}_{1}{ }^{a}$} & \multirow{4}{*}{$\begin{array}{c}\frac{P_{1} / P_{3}}{\text { No. of Plants }} \\
F_{1}\end{array}$} & \multirow{4}{*}{$\begin{array}{c}\mathbf{P}_{1} / \mathbf{P}_{3} / / \mathbf{P}_{1} \\
\text { No. of Plants } \\
\mathbf{B C}_{1}\end{array}$} \\
\hline & & & & \multicolumn{2}{|c|}{ No. of Plants } & \multirow{2}{*}{\multicolumn{3}{|c|}{$\begin{array}{c}\text { No. of Lines } \\
F_{2: 3} \mathbf{b} \\
\end{array}$}} & & \\
\hline & \multirow{2}{*}{$\mathbf{P}_{1}$} & \multirow{2}{*}{$\mathbf{P}_{2}$} & \multirow{2}{*}{$\mathbf{P}_{3}$} & \multirow{2}{*}{$\mathbf{F}_{1}$} & \multirow{2}{*}{$\mathbf{F}_{2}$} & & & & & \\
\hline & & & & & & $H R$ & Seg & $H S$ & & \\
\hline 0 & 15 & & & & 11 & $9^{c}$ & 0 & 0 & & 7 \\
\hline 0 & 3 & & & & 23 & 23 & 0 & 0 & & 25 \\
\hline 1 & & & & & 9 & $8^{c}$ & 0 & 0 & & 4 \\
\hline 2 & & & & & 3 & 3 & 0 & 0 & & 1 \\
\hline 3 & & & & 3 & 78 & 0 & 62 & 16 & 5 & 24 \\
\hline 4 & & 16 & 17 & 15 & 51 & 0 & 14 & $31^{\mathrm{d}}$ & 12 & 17 \\
\hline Total & 18 & 16 & 17 & 18 & 175 & 43 & 76 & 47 & 17 & 78 \\
\hline & & & & $\chi^{2 \mathrm{e}}$ & $=0.15$ & & $2: 1)=$ & & & $\chi_{(1: 1)}^{2}=0.21$ \\
\hline & & & & & & & $=0$ & & & $p=0.65$ \\
\hline
\end{tabular}

${ }^{\mathrm{a}} \mathrm{P}_{1}=\mathrm{CH} 09 \mathrm{~W} 89, \mathrm{P}_{2}=\mathrm{SY} 95-71, \mathrm{P}_{3}=\mathrm{MY}$ (Mianyang) $11 ;{ }^{\mathrm{b}} H R$, Seg, and $H S$ : homozygous resistant, segregating, and homozygous susceptible; ${ }^{\mathrm{c}}$ Insufficient seeds were gained from these $\mathrm{F}_{2}$ plants due to very late heading. They were assumed to be $H R ;{ }^{\mathrm{d}} \mathrm{Six} \mathrm{F}_{2}$ plants died in the greenhouse due to serious infection. They were assumed to be $H S$ or $S e g ;{ }^{e}$ Values for significance at $p=0.05$ are 3.83 for $1 d f$ and 5.99 for $2 d f$.

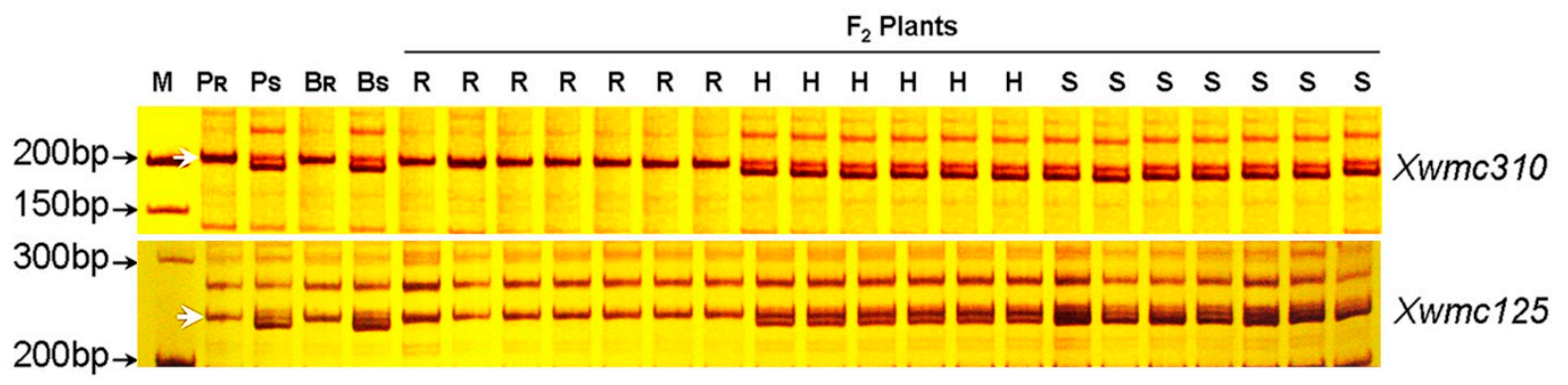

Figure 3. Silver-stained polyacrylamide gels showing simple sequence repeat (SSR) markers $X w m c 310$ and $X w m c 125$ flanking the $p m C H 89$ locus. $P_{R}$ and $P_{S}$ denote CH09W89 and SY95-71, respectively; $B_{R}$ and $B_{S}$ denote the resistant and susceptible bulks, respectively. Selected homozygous resistant $(R)$, homozygous susceptible $(S)$, and heterozygous $(H) \mathrm{F}_{2}$ plants from SY95-71/CH09W89 are included here. M, 100 bp DNA ladder; arrows on the left side indicate the fragment linked to the resistance gene. Arrows indicate the polymorphic bands.

\subsection{Identification of Microsatellite Markers Linked to pmCH89}

A total of 596 SSR markers, covering all 21 pairs of chromosomes, were used to screen polymorphisms between resistant (resistant parent and $\mathrm{Br}$ (bulked resistant)) and susceptible materials (susceptible parent and $B s$ (bulked susceptible)). About 156 (26.2\%) of the microsatellite primers chosen for initial screening were polymorphic between resistant and susceptible materials. Four markers, Xbarc193, Xbarc199, Xwmc125 (Figure 3), and Xwmc310 (Figure 3), were associated with pmCH89. Linkage analysis using the four markers on $\mathrm{F}_{2}$ plants and the powdery mildew response genotypes inferred from reactions of the $\mathrm{F}_{2: 3}$ families indicated that they were linked to the resistance gene. The three SSR markers, Xwmc125, Xbarc199, and Xwmc310, were located on the long arm of 
chromosome 4B, and Xbarc193 on the short arm of chromosome 4B [14] (http://wheat.pw.usda. gov/cgi-bin/graingenes), indicating that $p m C H 89$ is located on $4 \mathrm{~B}$. The $\mathrm{F}_{2}$ population segregated 1:2:1 for all four markers.

Analyses with Joinmap 4.0 also showed linkage between the markers and pmCH89; Xwmc310 and $X w m 125$ were close to the resistance gene with genetic distances of 3.1 and $2.7 \mathrm{cM}$, respectively, and Xbarc199 and Xbarc193 were more distant with respective genetic distances of 7.8 and $28.0 \mathrm{cM}$ (Figure 4).

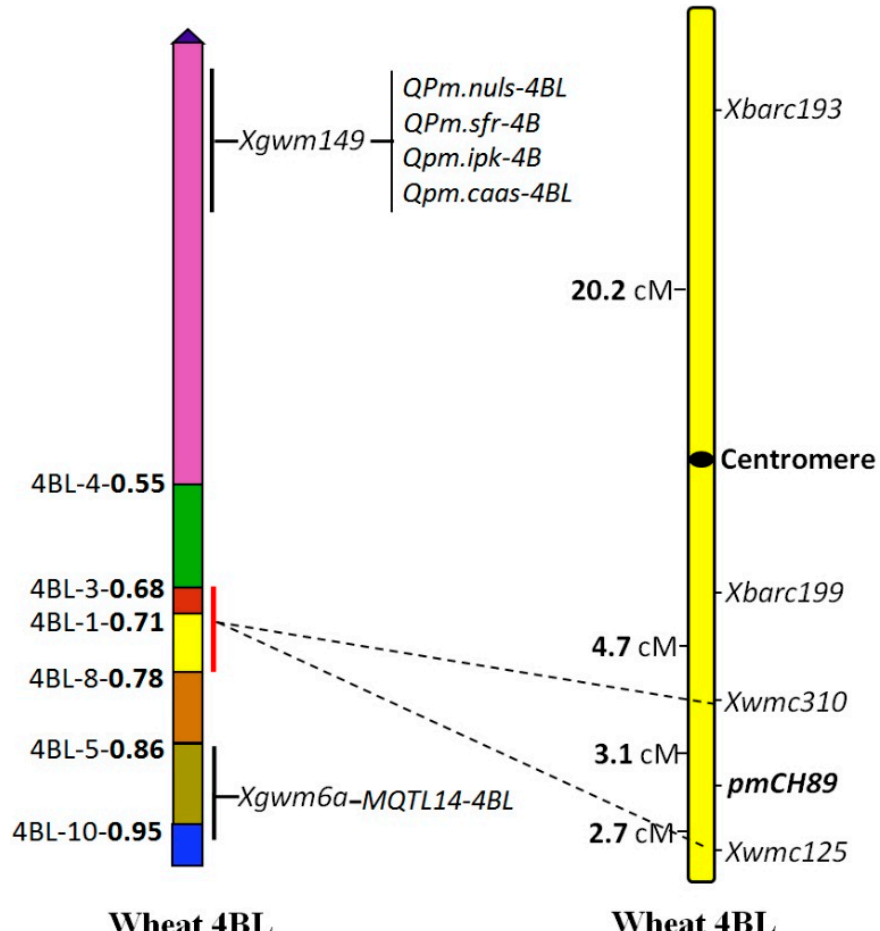

Figure 4. Genetic and deletion bin position of pmCH89 on chromosome 4BL.

\subsection{Chromosome Arm Assignment and Deletion Bin Mapping}

To determine the location of pmCH89 on chromosome 4B, the four SSR markers Xwmc125, Xbarc193, Xbarc199, and Xwmc310 (http://wheat.pw.usda.gov/cgi-bin/graingenes) were used to test a set of Chinese Spring (CS) nullitetrasomic and ditelosomic lines. The four microsatellite primer pairs amplified products of the expected sizes in CS and the CS nulli-tetrasomic lines N4AT4B and N4DT4B, but no PCR product was observed for the nulli-tetrasomic N4BT4A and Dt4BS lines (Figure 5a), except Xbarc193. Only Xbarc193 had PCR products in the ditelosomic line Dt4BS. Because amplified products of three markers were absent in the N4BT4A and Dt4BS lines, we confirmed the assignment of the linked microsatellite markers to the long arm of chromosome 4BL.

The deletion lines of CS chromosome 4BL were used to determine the physical bin locations of pmCH89 and its flanking markers. Xwmc310 and Xwmc125 were not detected in 4BL-4 and 4BL-3, and $X w m c 125$ was also absent in 4BL-1 (Figure 5b). The results indicated that $X w m c 310$ is located at 4BL bin $0.68-0.71$ and that $X w m c 125$ is at $4 \mathrm{BL}$ bin $0.71-0.78$. Therefore, the powdery mildew resistant gene pmCH89 could be assigned to 4BL bin $0.68-0.78$ (Figure 4). Based on its origin and map location, the recessive gene $\mathrm{pmCH} 89$ is apparently new. 


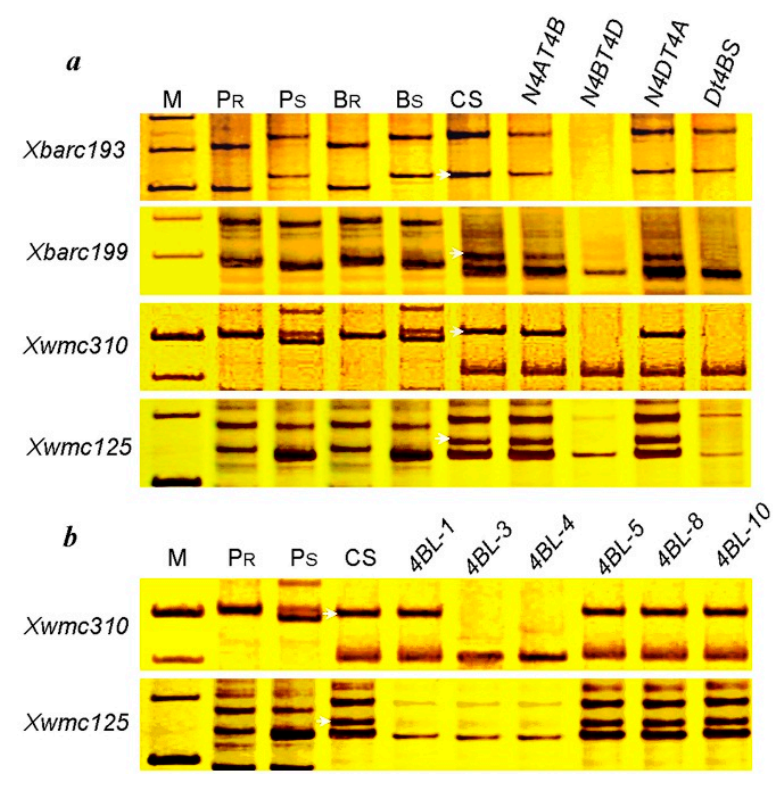

Figure 5. Amplification patterns of linked markers in CH09W89 $\left(P_{R}\right)$, SY95-71 $\left(P_{S}\right)$, resistant bulk $\left(B_{R}\right)$, susceptible bulk $\left(B_{S}\right)$, Chinese Spring (CS), nullisomic-tetrasomic (NT) 4B, ditelosomic (Dt) 4BS stocks (a); and 4BL deletion lines (b) of CS; Arrows indicate the critical bands.

\section{Discussion}

Exploitation of genetic variability, especially for genes conferring disease resistance, is essential for the development of new, improved plant varieties. The uncultivated relatives of wheat have provided some of the most important and widely used resistance genes which have been deployed in commercial cultivars around the world. Th. intermedium is an important perennial Triticeae species for wheat improvement due to its resistance to viral and fungal diseases. Some wheat-Th. intermedium derivatives have been found to be highly resistant to the fungus causing powdery mildew. For example, a resistance gene was recently found in partial amphiploids [15] and a substitution line 2E (2D), in which an E-chromosome of Th. intermedium was substituted for chromosome 2D in wheat [16]. CH09W89, a putative derivative of Th. intermedium accession Z1141, was produced by crossing and backcrossing TAI7045, a partial wheat-Th. intermedium amphiploid, with susceptible wheat cultivars and selecting for powdery mildew resistance. Line CH09W89 displayed good agronomic characteristics and also carried resistance to powdery mildew. However, there was no documentation of the chromosome content of this line. As all of the wheat parents in the pedigree of CH09W89 are highly susceptible, the resistance in that line is assumed to derive from Th. intermedium. Genetic segregation data clearly indicate the presence of a single recessive resistance gene in CH09W89 (Table 2). Two other powdery mildew resistance genes, $P m 40$ [10] and $P m 43$ [11], previously introgressed into common wheat from this donor species, were dominant. Given its action and chromosomal location, the resistance gene in CH09W89 seems to involve a novel locus.

In general, because of the presence of the $P h 1$ gene on wheat chromosome 5B, the recovery of a wheat-alien recombinant is difficult due to the lack of homoeologous pairing between the chromosomes of distant wild relatives and those of wheat. However, chromosomes of Th. intermedium and wheat can recombine $[17,18]$, suggesting that the transfer of alien chromosome segments by spontaneous 
chromosome translocations from this species to wheat chromosomes is possible. A good example of this appears to be the current study in which a small Th. intermedium-derived segmental translocation carrying resistance to powdery mildew has apparently been produced by backcrossing the resistant partial amphiploid TAI7045, derived from Th. intermedium, with a susceptible wheat cultivar [19]. However, GISH analysis of CH09W89 produced no cytological evidence for an alien translocation in this study. No apparent linkage drag was observed in the introgression line CH09W89. The gene pmCH89, based on widespread effectiveness and a unique chromosome location, must be either present in an intercalary cryptic translocation from Th. intermedium or a wheat gene derived from an unknown source. Cryptic alien chromosome transfers have been reported in other studies [20-22]. Further studies are needed to confirm the source of $\mathrm{pmCH} 89$.

In the present study, $\mathrm{pmCH} 89$ conferred full resistance at the seedling stage to seven different $\mathrm{Bgt}$ isolates (Table 1), and was mapped onto wheat chromosome arm 4BL with a different location from Pm40 (7BS) [10] and Pm43 (2DL) [11]. Among the currently designated and temporarily designated $P m$ genes, some of them confer recessive resistance. These include $P m 5$ on chromosome $7 \mathrm{BL}$, originally derived from $T$. dicoccum [7]; Pm9 and $m l R D 30$ on chromosome 7AL [7], Pm47 on chromosome 7BS, from T. aestivum [23]; Pm26 [7] and pm42 [24] derived from T. dicoccoides and mapped on chromosome 2BS; pmY212 on chromosome 5DL, originating from Ae. tauschii [25]; pm2026 on chromosome 5A ${ }^{\mathrm{m}} \mathrm{L}$, derived from T. monococcum [7]; MlHubel on chromosome 2DL, transferred from T. spelta [26]; and PmLK906 and $p m X$ [27], both located on chromosome 2AL, and derived from T. aestivum [7].

Several QTLs for adult plant resistance with major or minor effects on powdery mildew response were also mapped on chromosome 4BL in previous studies [8]. Among them, QPm.nuls-4BL, a major QTL with resistance contributed by Avocet, accounting for between $21.0 \%$ and $40.2 \%$ of the total phenotypic variation in a RIL population, was located on the region around Xgwm251 and Xgwm375 [28]. This QTL was at the same position as similar QTLs QPm.sfr-4B, Qpm.ipk-4B, and Qpm.caas-4BL, detected respectively in the Forno/Oberkulmer, Synthetic/Opata, and Fukuho-komugi/ Oligoculm populations [8]. Their location is very close to the centromere of chromosome 4B due to the close linkage to $\mathrm{Xgwm} 149$ [14], whereas in this study, $\mathrm{pmCH} 89$ was physically mapped on the intercalary bin $0.68-0.78$ of chromosome 4BL, about $3 \mathrm{cM}$ proximal to Xwmc125 (Figures 4 and 5). This would seem to be a different locus. Additionally, Marone et al. [9] detected a major QLT, MQTL14-4BL, locus for powdery mildew resistance from T. durum on 4BL between the markers Xbcd110 and Xgwm6a. This gene also has a different chromosomal location from pmCH89 because the distal flanking marker Xgwm6a for MQTL14-4BL is proximal to Xwmc125 with a genetic distance of $16 \mathrm{cM}$ [14] and its physical location is in chromosome 4BL distal bin 0.86-1.00 [29].

In this current work, linkage analysis showed that a putative Th. intermedium-derived powdery mildew resistance gene pmCH89 was flanked by Xwmc310 and Xwm125 (Figure 4). Between the flanking markers $X w m c 310$ and Xwmc125, a genetic distance of $5.8 \mathrm{cM}$ was found. This indicated that there was recombination between these loci as well as between them and the resistance gene. Interestingly, the markers, which span $5.8 \mathrm{cM}$ in the SY95-71/CH09W89 cross, cover approximately $23 \mathrm{cM}$ in the Synthetic/Opata cross [14]. This shows that the recombination rate in the present study is about three-fold lower than in a cross involving hexaploid wheat. These results suggest that pairing and crossovers between chromosome 4B and an unidentified fragment of Th. intermedium chromosome introgressed into $\mathrm{CH} 09$ W89 seem to be possible but at a reduced rate. In fact, such suppressed 
recombination is common in populations segregating for alien introgressions in plants. For example, powdery mildew resistance genes Pm12 and Pm27, introgressed into common wheat chromosome 6B from Aegilops speltoides and Triticum timopheevii, respectively, showed no recombination or low recombination between the alien segments $(6 \mathrm{~S}$ or $6 \mathrm{G})$ and the wheat chromosome $6 \mathrm{~B}$ [30,31].

It is reported that many of the resistance genes used in agriculture eventually become ineffective with the continual change of the pathogen's virulence structure [32]. Consequently, there is an urgent need to discover and transfer more powdery mildew resistance genes from alien sources, which represent an abundant genetic resource, to commercial cultivars. The present gene $p m C H 89$ identified herein was transferred into a commercial wheat background, and a range of powdery mildew resistant introgression lines have been obtained. Henceforth, these lines could be used in wheat breeding programs. Marker data showed that Xwmc125, Xbarc193, Xbarc199, and Xwmc310 were linked to $\mathrm{pmCH89}$. The locations of four linked microsatellite loci were verified with CS nulli-tetrasomic and ditelosomic stocks and deletion lines, and were further confirmed by assigning linked microsatellite markers to chromosome 4BL in the bin 0.68-0.78. Based on the genetic and physical bin maps, the powdery mildew resistance gene $p m C H 89$ was mapped on the interstitial region of chromosome 4BL and closely flanked by SSR markers $X w m c 310$ and $X w m c 125$, which were proximal at $3.1 \mathrm{cM}$ and distal at $2.7 \mathrm{cM}$, respectively, to the resistance gene. Because resistance to powdery mildew in many Chinese cultivars has been overcome by virulent races of the pathogen, $\mathrm{pmCH} 89$ and the identification of closely flanking markers may be beneficial for increasing the overall diversity of available resistance genes with the potential to provide more comprehensive and durable protection against the disease.

\section{Materials and Methods}

\subsection{Plant Materials}

The materials used in this study were Th. intermedium (accession Z1141), and TAI7045, a partial amphiploid developed by crossing common wheat cultivars with Th. intermedium accession Z1141. Wheat genotypes CH09W89, Jinchun 5, Jin T2250, Jintai 170, Jinmai 33, and Chinese Spring (CS) were obtained from laboratory germplasm stocks. CS nullisomic-tetrasomic (NT) stocks (N4AT4B, N4BT4D, and N4DT4A), ditelosomic (Dt) 4BS stock, and 4BL deletion lines (4BL-1, 4BL-3, 4BL-4, 4BL-5, 4BL-8, and 4BL-10) were obtained from Dr. B. Friebe, Wheat Genetic and Genomic Resources Center, Kansas State University, Manhattan, KS, USA. CH09W89 is a homogeneous $\mathrm{BC}_{2} \mathrm{~F}_{5}$-derived resistant wheat line from Jintai $170 /$ TAI7045//2*Jinmai 33. TAI7045 is the powdery mildew resistance gene donor for CH09W89, which was derived from the cross Jinchun 5/Z1141//Jin T2250.

Wheat cultivars Jingshuang 16, SY95-71, and Mianyang 11 (MY11) are all susceptible to wheat powdery mildew. To study the powdery mildew resistance of CH09W89, we developed segregating populations $\left(\mathrm{F}_{2}, \mathrm{~F}_{2}: 3\right.$, and $\left.\mathrm{BC}_{1}\right)$ by crossing $\mathrm{CH} 09 \mathrm{~W} 89$ with susceptible wheat cultivars $\mathrm{SY} 95-71$ and MY11. The $F_{1}$ was used for determining the dominance of the resistance and $F_{2}, F_{2}: 3$, and $\mathrm{BC}_{1}$ were tested for segregation of powdery mildew resistance. An $\mathrm{F}_{2}$ population and derived $\mathrm{F}_{2: 3}$ lines from SY95-71/CH09W89 were used for further microsatellite screening and gene mapping. The mapping population was comprised of $175 \mathrm{~F}_{2}$ plants and 166 derived $\mathrm{F}_{2: 3}$ families, the difference being due to insufficient seeds of nine $\mathrm{F}_{2}$ plants. 


\subsection{Cytogenetic Analysis}

Genomic in situ hybridization is a powerful molecular cytogenetic technique to identify alien chromatin in the wheat background. GISH analysis was performed using a similar protocol to that described by Han et al. [33]. In this study, Th. intermedium Z1141 genomic DNA was used as a probe and the CS genomic DNA was used as blocker DNA.

\subsection{Evaluation of Powdery Mildew Responses}

Seven isolates of the prevailing local B. graminis f. sp. tritici (Bgt) pathotypes provided by the Plant Protection Institute, Chinese Academy of Agricultural Sciences (Table 1), were used for resistance tests in the seedling stage. Using Jingshuang 16 as a control, CH09W89 and the parental lines were grown in $70 \times 45 \times 18 \mathrm{~cm}$ flat plastic trays. When the first leaves were fully expanded, inoculations were performed by dusting conidiospores from sporulating seedlings of Chancellor onto the test seedlings according to the method described by Xiang [34]. Host infection types (ITs) were scored 2-3 weeks after inoculation, when the susceptible check Jingshuang 16 became heavily infected, using a $0-4$ rating scale [35], where $0=$ no visible symptoms, $0 ;=$ necrotic flecks, $1=$ necrosis with low sporulation, $2=$ necrosis with moderate sporulation, $3=$ no necrosis with moderate to high sporulation, and $4=$ no necrosis with full sporulation. Scores of $0-2$ were classified as resistant and 3-4 as susceptible.

To determine the genetics of resistance in CH09W89, E09, which is a prevalent pathotype in the Beijing area and avirulent on CH09W89, but is virulent on SY95-71 and MY (Mianyang) 11, was used to test $\mathrm{F}_{1}, \mathrm{~F}_{2}, \mathrm{~F}_{2: 3}$, and $\mathrm{BC}_{1}$ populations derived from $\mathrm{SY} 95-71 / \mathrm{CH} 09 \mathrm{~W} 89$ and $\mathrm{CH} 09 \mathrm{~W} 89 /$ MY11//CH09W89 (Table 2). All seeds from the parents, $F_{1}, F_{2}, F_{2: 3}$, and $\mathrm{BC}_{1}$ populations were planted in the greenhouse. Twenty seeds of each parent and $F_{1}, 175$ seeds of $F_{2}, 78$ seeds of $B_{1}$, and 20-25 seeds for each of the $\mathrm{F}_{2}$-derived $\mathrm{F}_{2: 3}$ families were planted randomly in a $100 \mathrm{~cm}$ row, $25 \mathrm{~cm}$ apart. Susceptible spreaders of Jingshuang 16 and SY95-71 were planted in every 10th row for each population. The predominant Bgt race E09 was used for adult plant testing and the spreaders were artificially inoculated two times at the seedling stage. Adult plant reactions were scored twice, at the ear emergence stage and at the milky ripe stage, using the 0-4 scale previously described. To determine the genotypes of $\mathrm{F}_{2}$ plants from the cross of $\mathrm{CH} 09 \mathrm{~W} 89$ with $\mathrm{SY} 95-71$, the $\mathrm{F}_{2}$-derived $\mathrm{F}_{3}$ families were tested with the same race used in the $\mathrm{F}_{2}$ tests.

\subsection{Molecular Marker Analysis}

Genomic DNA, extracted from young seedling leaf tissue collected from the $\mathrm{F}_{2}$ individuals from which the $\mathrm{F}_{2: 3}$ families originated, were used for molecular analysis. SSR markers linked to the resistance gene were identified by bulked segregant analysis (BSA). Equal amounts of DNA from 10 resistant $\mathrm{F}_{2}$ segregants were pooled into a resistant bulk, and DNA from 10 susceptible $F_{2}$ segregants were pooled into a susceptible bulk according to Michelmore et al. [36]. The resistant parent, susceptible parent, resistant bulk $(B r)$, and susceptible bulk $(B s)$ were then screened by genome and chromosome specific markers from across the wheat genome. Markers that were polymorphic between the resistant and susceptible parents and bulks were used to genotype the $\mathrm{F}_{2: 3}$ lines and for linkage analysis. 
Wheat microsatellite markers were used to detect polymorphism among parents, and resistant and susceptible bulks. The polymorphism markers were genotyped in $\mathrm{F}_{2}$ individuals to determine genetic linkage between the powdery mildew resistance gene(s) and markers.

PCR was performed in a $20 \mu \mathrm{L}$ solution comprised of $80-100$ ng template DNA, $2 \mu \mathrm{L} 10 \times$ buffer (10 mM Tris-HCl, pH 8.3, $50 \mathrm{mM} \mathrm{KCl}, 1.5 \mathrm{mM} \mathrm{MgCl} 2$ ), $0.2 \mathrm{mM}$ of each dNTP, 1 unit Taq DNA polymerase, $0.25 \mu \mathrm{M}$ of each primer. Amplification was performed at $94{ }^{\circ} \mathrm{C}$ for $5 \mathrm{~min}$ initial denaturation, 35 cycles each consisting of $45 \mathrm{~s}$ at $94{ }^{\circ} \mathrm{C}$ for denaturation, $45 \mathrm{~s}$ at either 50,55 or $60{ }^{\circ} \mathrm{C}$ (based on primer annealing temperature), $1 \mathrm{~min}$ at $72{ }^{\circ} \mathrm{C}$ for extension; and finally a $10 \mathrm{~min}$ extension step at $72{ }^{\circ} \mathrm{C}$ before cooling to $4{ }^{\circ} \mathrm{C}$. After PCR amplification, $12 \mu \mathrm{L}$ of formamide loading buffer $(0.4 \mathrm{~g} / \mathrm{mL}$ sucrose, $1 \mathrm{mg} / \mathrm{mL}$ bromophenol blue, and $1 \mathrm{mg} / \mathrm{mL}$ xylene cyanol) was added to each PCR product. Then, 4-6 $\mu \mathrm{L}$ of each sample was loaded on $8 \%$ non-denaturing polyacrylamide gels (Acr:Bis $=29: 1$ ) and separated at $150 \mathrm{~V}$ for approximately $2 \mathrm{~h}$, then visualized by silver staining. PCR for each SSR marker was performed in a PTC200 Peltier Thermal Cycler (Bio-Rad Laboratories Inc., Hercules, CA, USA).

\subsection{Data Analysis and Chromosomal Assignment}

The goodness-of-fit of observed phenotypes and expected segregation ratios was determined by $\chi$-square tests $\left(\chi^{2}\right)$. Linkages between markers and the resistance gene were determined using Joinmap 4.0 software [37] with a LOD threshold 3.0. Map distances were determined by using the Kosambi mapping function.

Chromosomal locations of linked microsatellite markers were confirmed by using CS homoeologous group 4 nullitetrasomic, ditelosomic and lines 4BL-4 (FL 0.55), 4BL-3 (FL 0.68), 4BL-1 (FL 0.71), 4BL-8 (FL 0.78), 4BL-5 (FL 0.86), and 4BL-10 (FL 0.95). Markers were located to chromosome bins by determining the smallest deletion bin possessing them.

\section{Conclusions}

A new powdery mildew resistance gene, tentatively designated as $\mathrm{pmCH} 89$, was found in a putative wheat-Th. intermedium introgression line developed by crossing the resistant partial amphiploid TAI7045 with susceptible cultivars, and the resistance is effective against the existing powdery mildew races in China, including the most widely virulent and predominant pathotypes. The gene was physically mapped on the intercalary bin $0.68-0.78$ of chromosome 4BL and closely flanked by markers $X w m c 310$ and Xwmc125. pmCH89, together with the identified closely linked markers, could be useful in marker-assisted selection for improving powdery mildew resistance in wheat breeding programs.

\section{Acknowledgments}

This project was financially supported by the National Natural Science Foundation of China (31171839), Shanxi Financial Support for Agriculture Project (2014ZYFZ-03), the Program for Shanxi Innovative Research Teams (2013131025), the Program for Shanxi Key laboratory construction (2015012001-13), and Shanxi Provincial Program of Science and Technology (20130311001-5). We are grateful to Ian Dundas (The University of Adelaide, Adelaide, Australia) for critical reading and editing this manuscript. 


\section{Author Contributions}

Zhijian Chang, and Xiaojun Zhang designed the experiments; Liyuan Hou, Xin Li, Huizhen Yang, Haixian Zhan, Huijuan Guo, and Linyi Qiao performed the experiments; Zhijian Chang, Xiaojun Zhang, and Juqing Jia provided materials; Linyi Qiao, and Liyuan Hou analysed data; Liyuan Hou, Zhijian Chang, and Juqing Jia wrote the paper.

\section{Conflicts of Interest}

The authors declare no conflict of interest.

\section{References}

1. Zhuang, Q.S.; Li, Z.S. Present status of wheat breeding and related genetic study in China. Wheat Inf. Serv. 1993, 76, 1-5.

2. Morgounov, A.; Tufan, H.A.; Sharma, R.; Akin, B.; Bagei, A.; Braun, H.J.; Kaya, Y.; Keser, M.; Payne, T.S.; Sonder, K.; et al. Global incidence of wheat rusts and powdery mildew during 1969-2010 and durability of resistance of winter wheat variety Bezostaya 1. Eur. J. Plant Pathol. 2012, 132, 323-340.

3. Zhao, Z.H.; Sun, H.G.; Song, W.; Lu, M.; Huang, J.; Wu, L.F.; Wang, X.M.; Li, H.J. Genetic analysis and detection of the gene MlLX99 on chromosome 2BL conferring resistance to powdery mildew in the wheat cultivar Liangxing 99. Theor. Appl. Genet. 2013, 126, 3081-3089.

4. Line, R.F.; Chen, X.M. Success in breeding for and managing durable resistance to wheat rusts. Plant Dis. 1995, 79, 1254-1255.

5. Zhan, H.X.; Li, G.R.; Zhang, X.J.; LI, X.; Guo, H.J.; Gong, W.P.; Jia, J.Q.; Qiao, L.Y. Chromosomal location and comparative genomics analysis of powdery mildew resistance gene Pm51 in a putative wheat-Thinopyrum ponticum introgression line. PLoS ONE 2014, 9, e113455.

6. Petersen, S.; Lyerly, J.H.; Worthington, M.L.; Parks, W.R.; Cowger, C.; Marshall, D.S.; Brown-Guedira, G.; Murphy, J.P. Mapping of powdery mildew resistance gene Pm53 introgressed from Aegilops speltoides into soft red winter wheat. Theor. Appl. Genet. 2015, 128, 303-312.

7. McIntosh, R.A.; Yamazaki, Y.Y.; Dubcovsky, J.; Rogers, J.; Morris, C.; Appels, R.; Xia, X.C. Gene Catalogue 2013: Catalogue of gene symbols for wheat. 12th International Wheat Genetics Symposium: Yokohama, Japan, 2013. Available online: http://www.shigen.nig.ac.jp/wheat/ komugi/genes/macgene/2013/GeneSymbol.pdf (accessed on 8 June 2015).

8. Li, Z.F.; Lan, C.X.; He, Z.H.; Singh, R.P.; Rosewarne, G.M.; Chen, X.M.; Xia, X.C. Overview and application of QTL for adult plant resistance to leaf rust and powdery mildew in wheat. Crop Sci. 2014, 54, 1907-1925.

9. Marone, D.; Russo, M.A.; Laidò, G.; Vita, P.D.; Papq, R.; Blanco, A.; Gadaleta, A.; Rubiales, D.; Mastrangelo, A.M. Genetic basis of qualitative and quantitative resistance to powdery mildew in wheat: From consensus regions to candidate genes. BMC Genomics 2013, 14, 562.

10. Luo, P.G.; Luo, H.Y.; Chang, Z.J.; Zhang, H.Y.; Zhang, M.; Ren, Z.L. Characterization and chromosomal location of $P m 40$ in common wheat: A new gene for resistance to powdery mildew derived from Elytrigia intermedium. Theor. Appl. Genet. 2009, 118, 1059-1064. 
11. He, R.L.; Chang, Z.J.; Yang, Z.J.; Zhan, H.X.; Zhang, X.J.; Liu, J.X. Inheritance and mapping of powdery mildew resistance gene Pm43 introgressed from Thinopyrum intermedium into wheat. Theor. Appl. Genet. 2009, 118, 1173-1180.

12. Friebe, B.; Jiang, J.; Raupp, W.J.; McIntosh, R.A.; Gill, B.S. Characterization of wheat-alien translocations conferring resistance to diseases and pests: Current status. Euphytica 1996, 91, 59-87.

13. Liu, J.; Chang, Z.J.; Zhang, X.J.; Yang, Z.J.; Li, X.; Jia, J.Q.; Zhan, H.X.; Guo, H.J.; Wang, J.M. Putative Thinopyrum intermedium-derived stripe rust resistance gene $\operatorname{Yr} 50$ maps on wheat chromosome arm 4BL. Theor. Appl. Genet. 2013, 126, 265-274.

14. Somers, D.J.; Isaac, P.; Edwards, K. A high-density microsatellite consensus map for bread wheat (Triticum aestivum L.). Theor. Appl. Genet. 2004, 109, 1105-1114.

15. Chang, Z.J.; Zhang, X.J.; Yang, Z.J.; Zhan, H.X.; Li, X.; Liu, C.; Zhang, C.Z. Characterization of a partial wheat-Thinopyrum intermedium amphiploid and its reaction to fungal diseases of wheat. Hereditas 2010, 147, 304-312.

16. Liu, S.B.; Wang, H.G. Characterization of a wheat-Thinopyron intermedium substitution line with resistance to powdery mildew. Euphytica 2005, 143, 229-233.

17. Ayala-Navarrete, L.; Thompson, N.; Ohm, H.; Anderson, J. Molecular markers show a complex mosaic pattern of wheat-Thinopyrum intermedium translocations carrying resistance to BYDV. Theor. Appl. Genet. 2010, 121, 961-970.

18. Wang, M.J.; Zhang, Y.; Lin, Z.S.; Ye, X.G.; Yuan, Y.P.; Ma, W.; Xin, Z.Y. Development of EST-PCR markers for Thinopyrum intermedium chromosome 2Ai\#2 and their application in characterization of novel wheat-grass recombinants. Theor. Appl. Genet. 2010, 121, 1369-1380.

19. Tang, X.Q.; Shi, D.; Xu, J.; Li, Y.L.; Li, W.J.; Ren, Z.L.; Fu, T.H. Molecular cytogenetic characteristics of a translocation line between common wheat and Thinopyrum intermedium with resistance to powdery mildew. Euphytica 2014, 197, 201-210.

20. Dong, Y.; Bu, X.; Luan, Y.; He, M.; Liu, B. Molecular characterization of a cryptic wheat-Thinopyrum intermedium translocation line: Evidence for genomic instability in nascent allopolyploid and aneuploid lines. Genet. Mol. Biol. 2004, 27, 237-241.

21. Huang, Q.; Li, X.; Chen, W.Q.; Xiang, Z.P.; Zhong, S.F.; Chang, Z.J.; Zhang, M.; Zhang, H.Y.; Tan, F.Q.; Ren, Z.L.; et al. Genetic mapping of a putative Thinopyrum intermedium-derived stripe rust resistance gene on wheat chromosome 1B. Theor. Appl. Genet. 2014, 127, 843-853.

22. Caceres, M.E.; Pupilli, F.; Ceccarelli, M.; Vaccino, P.; Sarri, V.; Pace, C.D. Cryptic introgression of Dasypyrum villosum parental DNA in wheat lines derived from intergeneric hybridization. Cytogenet. Genome Res. 2012, 136, 75-81.

23. Xiao, M.G.; Song, F.J.; Jiao, J.F.; Wang, X.M.; Xu, H.X.; Li, H.J. Identification of the gene Pm47 on chromosome 7BS conferring resistance to powdery mildew in the Chinese wheat landrace Hongyanglazi. Theor. Appl. Genet. 2013, 126, 1397-1403.

24. Hua, W.; Liu, Z.J.; Zhu, J.; Xie, C.J.; Yang, T.; Zhou, Y.L.; Duan, X.Y.; Sun, Q.X.; Liu, Z.Y. Identification and genetic mapping of $P m 42$, a new recessive wheat powdery mildew resistance gene derived from wild emmer (Triticum turgidum var. dicoccoides). Theor. Appl. Genet. 2009, $119,223-230$. 
25. Sun, X.L.; Liu, D.; Zhang, H.; Huo, N.; Zhou, R.; Jia, J. Identification and mapping of two new genes conferring resistance to powdery mildew from Aegilops tauschii (Coss.) Schmal. J. Integr. Plant Biol. 2006, 48, 1204-1209.

26. Peng, F.X.; Song, N.; Shen, H.X.; Wu, H.B.; Dong, H.T.; Zhang, J.; Li, Y.H.; Peng, H.R.; Ni, Z.F.; Liu, Z.Y.; et al. Molecular mapping of a recessive powdery mildew resistance gene in spelt wheat cultivar Hubel. Mol. Breed. 2014, 34, 491-500.

27. Fu, B.S.; Chen, Y.; Li, N.; Ma, H.Q.; Kong, Z.X.; Zhang, L.X.; Jia, H.Y.; Ma, Z.Q. pmX: A recessive powdery mildew resistance gene at the $P m 4$ locus identified in wheat landrace Xiaohongpi. Theor. Appl. Genet. 2013, 126, 913-921.

28. Lillemo, M.; Asalf, B.; Singh, R.P.; Huerta-Espino, J.; Chen, X.M.; He, Z.H.; Bjørnstad, A. The adult plant rust resistance loci $\operatorname{Lr} 34 / Y r 18$ and $L r 46 / Y r 29$ are important determinants of partial resistance to powdery mildew in bread wheat line Saar. Theor. Appl. Genet. 2008, 116, 1155-1166.

29. Marone, D.; Laidò, G.; Gadaleta, A.; Colasuonno, P.; Ficco, D.B.; Giancaspro, A.; Giove, S.; Panio, G.; Russo, M.A.; de Vita, P.; et al. A high-density consensus map of A and B wheat genomes. Theor. Appl. Genet. 2012, 125, 1619-1638.

30. Jia, J.; Devos, K.M.; Chao, S.; Miller, T.E.; Reader, S.M.; Gale, M.D. RFLP-based maps of the homoelogous group-6 chromosomes of wheat and their application in the tagging of Pm12, a powdery mildew resistance gene transferred from Aegilops speltoides to wheat. Theor. Appl. Genet. 1996, 92, 559-565.

31. Jarve, K.; Peusha, H.O.; Tsymbalova, J.; Tamm, S.; Devos, K.M.; Enno, T.M. Chromosomal location of a Triticum timopheevii-derived powdery mildew resistance gene transferred to common wheat. Genome 2000, 43, 377-381.

32. McDonald, B.A.; Linde, C. The population genetics of plant pathogens and breeding strategies for durable resistance. Euphytica 2002, 124, 163-180.

33. Han, F.; Lamb, J.C.; Bircher, J.A. High frequency of centromere inactivation resulting in stable dicentric chromosomes of maize. Proc. Natl. Acad. Sci. USA 2006, 103, 3238-3243.

34. Xiang, Q.J.; Sheng, B.Q.; Zhou, Y.L.; Duan, X.Y.; Zhang, K.C. Analyses of resistance genes of three differential varieties to the isolates of Blumeria graminis f. sp. tritici in wheat. Acta Agric. Boreali-Sin. 1994, 9, 94-97.

35. Xie, C.J.; Sun, Q.X.; Ni, Z.F.; Yang, T.; Nevo, E.; Fahima, T. Chromosomal location of a Triticum dicoccoides-derived powdery mildew resistance gene in common wheat by using microsatellite markers. Theor. Appl. Genet. 2003, 106, 341-345.

36. Michelmore, R.M.; Paran, I.; Kesseli, R.V. Identification of markers linked to disease-resistance genes by bulked segregant analysis: A rapid method to detect markers in specific genomic regions by using segregating populations. Proc. Natl. Acad. Sci. USA 1991, 88, 9828-9832.

37. Ooijen, J.W.; Voorips, R.E. JoinMap ${ }^{\mathrm{TM}}$ Version 3.0: Software for the Calculation of Genetic Linkage Maps; University and Research Center: Wageningen, The Netherlands, 2001.

(C) 2015 by the authors; licensee MDPI, Basel, Switzerland. This article is an open access article distributed under the terms and conditions of the Creative Commons Attribution license (http://creativecommons.org/licenses/by/4.0/). 